\title{
Unusual manifestation of brucellosis
}

\author{
Ranjbar Mitra* \\ Department of Infectious Diseases, Firoozgar Hospital, Tehran University of Medical Sciences, Tehran, Iran
}

\begin{abstract}
The unusual manifestations of brucellosis as an endemic disease involving multiple organ systems include headache, confusion, acute abdomen, psoas abscess, endocarditis, perinephric mass, insulin-resistance, and cauda-equina syndrome. In this paper we report a patient with such situations that was initially diagnosed and treated for CCHF with partial improvement of symptoms after Ribavirin therapy and readmission for brucellosis and improvement of symptoms after combination therapy for the later diagnosis. A 31-year-old male patient was attended with intermittent fever and chill plus myalgia, melena, ad hematuria for one week ago. He also had generalized abdominal pain and loss of appetite with body mass index of $19 \mathrm{~kg} / \mathrm{m}^{2}$. He had a history of ten neonatal deaths of livestock in last month. In laboratory tests the liver enzymes were raised and pancytopenia was present. Patient received therapeutic dose of ribavirin plus apotel and the general status was improved. After one-month patient was readmitted for fever plus right hip and knee pain and the brucella IgG was in borderline level (10.36). He received treatment for brucellosis including amikacin, doxycycline, and rifampin. The Wright and coomb's Wright tests were positive. The general health was improved, and patient was discharged with administration of doxycycline $100 \mathrm{mg}$ twice a day, and rifampin $600 \mathrm{mg}$ once a day. Totally, according to the reported case, it should be emphasized that Ribavirin is effective in treatment of brucellosis.
\end{abstract}

\section{Introduction}

The unusual manifestations of brucellosis as an endemic disease involving multiple organ systems include headache, confusion, acute abdomen, psoas abscess, endocarditis, perinephric mass, insulinresistance, and cauda-equina syndrome [1-3]. Ribavirin, a guanosine analogue that produces broad-spectrum activity against several RNA and DNA viruses, was firstly discovered by Witkowski et al in 1972 $[4,5]$. While initially it was approved only for the management of severe respiratory syncytial virus infection in children, it has been used for the treatment of Lassa fever virus infection, influenza A and B, and other pathogenic germs [4-7].

Ribavirin has been utilized as an antiviral drug for several decades [5]. Also, there are some reports about efficacy in the treatment of brucellosis [6]; but this matter is not yet completely established. In this paper we report a patient with such situations that was initially diagnosed and treated for CCHF with partial improvement of symptoms after viral therapy with Ribavirin and readmission for brucellosis and improvement of symptoms after combination therapy for the later diagnosis.

\section{Case presentation}

A 31-year-old male patient was attended with intermittent fever and chill plus myalgia, melena, ad hematuria for one week ago. He also had generalized abdominal pain and loss of appetite with body mass index of $19 \mathrm{~kg} / \mathrm{m}^{2}$. He had a history of ten neonatal deaths of livestock in last month and also use of local dairy products. Intermittent diarrhea and constipation was reported. The fever was in afternoon. The right hip pain was accompanied with claudication that was improved after three days and then the left foot pain was initiated. In laboratory tests the liver enzymes were raised and pancytopenia was present (Table 1). The Wright and 2ME-Wright tests were negative. However, the family history was positive for brucellosis (brother).

Patient received ribavirin with therapeutic dose plus apotel injection and then the general status was improved. The leukopenia
Table 1. Initial and final laboratory tests

\begin{tabular}{|c|c|c|}
\hline Laboratory tests & Initial & Final \\
\hline Leukocyte & 3100 & 10400 \\
\hline Erythrocyte & $5.03 \mathrm{mil}$ & $4.99 \mathrm{mil}$ \\
\hline Hemoglobin & 9.8 & 9.6 \\
\hline Platelet & 110 & 349 \\
\hline Urea & 24 & 34 \\
\hline Creatinine & 1.1 & 0.9 \\
\hline SGOT & 530 & 92 \\
\hline SGPT & 451 & 210 \\
\hline Alkaline Phosphatase & 247 & 282 \\
\hline
\end{tabular}

and thrombocytopenia were normalized, and the liver enzymes were decreased (Table 1). The Crimean-Congo hemorrhagic fever (CCHF) test was negative. Also, the hepatitis B and HIV tests all were negative. The patient was discharged with good general health.

After one-month patient was readmitted for fever plus right hip and knee pain and the brucella IgG was in borderline level (10.36). He received treatment for brucellosis including amikacin, doxycycline, and rifampin. The Wright and coomb's Wright tests were positive. Liver enzymes were normal (SGOT=49.9 U/L; SGPT=38.1; Alkaline phosphatase $=138 \mathrm{IL} / \mathrm{L}$ ). There was mild anemia (Hemoglobin=9.5). Blood culture was positive for pseudomonas and urine cultures were negative. The general health was improved, and patient was discharged with administration of doxycycline $100 \mathrm{mg}$ twice a day, and rifampin $600 \mathrm{mg}$ once a day.

${ }^{*}$ Correspondence to: Ranjbar Mitra, Department of Infectious Diseases, Firoozgar Hospital, Tehran University of Medical Sciences, Tehran, Iran, Tel: 00989125049951, E-mail: mitraranjbar@yahoo.com

Received: November 11, 2019; Accepted: November 18, 2019; Published: November 21, 2019 


\section{Discussion}

Crimean-Congo hemorrhagic fever is a tick-borne disease often associated with hemorrhagic manifestations and high case fatality rate of 10 to 50 percent $[7,8]$. It may respond to Ribavirin but response by brucellosis is less reported (6). Both infectious causes, such as brucellosis and non-infectious causes may resemble CCHF [9]. Especially physicians working in endemic regions should have knowledge of probably longer incubation periods after a tick bite [10]. Ayatollahi et al. [11] reported nine CCHF cases from Iran who all of them were negative for brucellosis. But differentiation from each other is not mandatory because both would respond to Ribavirin [12].

Metin et al reported a case of brucellosis mimicking CrimeanCongo hemorrhagic fever [13]. Our patient may be such case. It means that the reported patient may not be actually a CCHF infection case and even the initial admission may have been due to brucellosis but would respond to Ribavirin. Also, Karakeçili et al also presented a case of brucellosis and Crimean-Congo hemorrhagic fever coinfection in an endemic area [14]. Our reported case may also have been a coinfection.

Similar to our patient a 13-year-old boy was reported by Almiş et al as a case of brucellosis misdiagnosed as Crimean-Congo hemorrhagic fever [15]. On the other hand, for negative suspected Crimean-Congo hemorrhagic fever cases in an endemic area sub-clinical infection with Crimean-Congo hemorrhagic fever virus should not be remembered because Ribavirin would treat both infections $[16,17]$. Totally, according to the reported case, it should be emphasized that Ribavirin is effective in treatment of brucellosis.

\section{References}

1. Kaya O, Avşar K, Zeynep Akçam F (2011) Unusual manifestations of brucellosis. Arch Med Sci 7: 173-175.

2. Jayakumar RV, Al-Aska AK, Subesinghe N, Wright SG (1988) Unusual presentation of culture positive brucellosis. Postgrad Med J 64: 118-120. [Crossref]
3. Khorvash F, Keshteli AH, Behjati M, Salehi M, Emami Naeini A (2007) An unusual presentation of brucellosis, involving multiple organ systems, with low agglutinating titers: a case report. J Med Case Rep 1: 53.

4. Loustaud-Ratti V, Debette-Gratien M, Jacques J, Alain S, Marquet P et al. (2016) Ribavirin: Past, present and future. World J Hepatol 8: 123-130. [Crossref]

5. Thomas E, Ghany MG, Liang TJ (2012) The application and mechanism of action of ribavirin in therapy of hepatitis C. Antivir Chem Chemother 23: 1-12. [Crossref]

6. Duygu F, Sari T, Kaya T, Bulut N (2017) Brucellosis in Patients with Crimean-Congo Hemorrhagic Fever. J Arthropod Borne Dis 11: 463-468. [Crossref]

7. Shayan S, Bokaean M, Shahrivar MR, Chinikar S (2015) Crimean-Congo Hemorrhagic Fever. Lab Med 46: 180-189.

8. Bente DA, Forrester NL, Watts DM, McAuley AJ, Whitehouse CA, et al. (2013) Crimean-Congo hemorrhagic fever: history, epidemiology, pathogenesis, clinical syndrome and genetic diversity. Antiviral Res 100: 159-189. [Crossref]

9. Kara SS, Kara D, Fettah A (2016) Various clinical conditions can mimic CrimeanCongo hemorrhagic fever in pediatric patients in endemic regions. J Infect Public Health 9: 626-632. [Crossref]

10. Kaya A, Engin A, Güven AS (2011) Crimean-Congo hemorrhagic fever disease due to tick bite with very long incubation periods. Int J Infect Dis 15: e449-e452. [Crossref]

11. Ayatollahi J, Shahcheraghi SH, Mirjalili M (2015) Report of nine cases of CrimeanCongo haemorrhagic fever From Iran. Niger Med J 56: 156-159. [Crossref]

12. Flusin O, Iseni F, Rodrigues R (2010) Crimean-Congo hemorrhagic fever: basics for general practitioners. Med Trop (Mars) 70: 429-438. [Crossref]

13. Metin O, Teke TA, Gayretli Aydin ZG (2015) A case of brucellosis mimicking CrimeanCongo hemorrhagic fever. J Infect Public Health 8: 302-304. [Crossref]

14. Karakeçili F, Çıkman A, Akın H, Gülhan B, Özçiçek A (2016) A case of brucellosis and Crimean-Congo hemorrhagic fever coinfection in an endemic area. Mikrobiyol Bul 50: 322-327. [Crossref]

15. Almiș H, Yakıncı C (2012) A case of brucellosis misdiagnosed as Crimean-Congo hemorrhagic fever. Mikrobiyol Bul 46: 475-479. [Crossref]

16. Tanyel E, Sunbul M, Fletcher TE, Leblebicioglu H (2016) Aetiology of PCR negative suspected Crimean-Congo hemorrhagic fever cases in an endemic area. Pathog Glob Health 110: 173-177. [Crossref]

17. Bodur H, Akinci E, Ascioglu S, Öngürü P, Uyar Y (2012) Subclinical infections with Crimean-Congo hemorrhagic fever virus, Turkey. Emerg Infect Dis 18: 640-642. [Crossref]

Copyright: (C2019 Mitra R. This is an open-access article distributed under the terms of the Creative Commons Attribution License, which permits unrestricted use, distribution, and reproduction in any medium, provided the original author and source are credited. 